\title{
Heat-pipe enhanced solar-assisted heat pump water heater
}

\author{
B.J. Huang ${ }^{\text {a,* }}$, J.P. Lee ${ }^{\text {a }}$, J.P. Chyng ${ }^{b}$ \\ a Department of Mechanical Engineering, National Taiwan University, Taipei 106, Taiwan \\ ${ }^{\mathrm{b}}$ Department of Electrical Engineering, Chinmin College, Toufen, Miaoli, Taiwan
}

Received 17 October 2003; received in revised form 20 May 2004; accepted 10 August 2004

Available online 21 September 2004

Communicated by: Associate Editor Charles Kutscher

\begin{abstract}
A heat-pipe enhanced solar-assisted heat pump water heater (HPSAHP) is studied. HPSAHP is a heat pump with dual heat sources that combines the performance of conventional heat pump and solar heat pipe collector. HPSAHP operates in heat-pump mode when solar radiation is low and in heat-pipe mode without electricity consumption when solar radiation is high. HPSAHP can thus achieve high energy efficiency. A prototype was designed and built in the present study. An outdoor test for a HPSAHP in the present study has shown that COP of the hybrid-mode operation can reach 3.32, an increase of $28.7 \%$ as compared to the heat-pump mode COP (2.58).
\end{abstract}

(C) 2004 Elsevier Ltd. All rights reserved.

Keywords: Solar heat pump; Solar thermal; Heat pump; Solar water heater

\section{Introduction}

The New Energy Center at National Taiwan University has been devoted to the development of solar-assisted heat pump water heater (SAHP) since 1997. Several types of SAHP have been designed and tested. The SAHP consists of a Rankine refrigeration cycle coupled with a solar collector that acts as an evaporator. The refrigerant is directly expanded inside the evaporator to absorb the solar energy. By a proper design of the Rankine cycle and the solar collector for a specific operating condition, heat may be absorbed from, rather rejected to, the ambient. That is, the SHAP can absorb heat from both solar radiation and ambient air simultaneously (Huang and Chyng,

\footnotetext{
* Corresponding author. Tel.: +886 22363 4790/2362 4790; fax: +886223640549.

E-mail address: bjhuang@seed.net.tw (B.J. Huang).
}

2001). Huang and Chyng $(1998,1999)$ first proposed the design of an integral-type solar-assisted heat pump water heater (ISAHP) that integrates the heat pump, solar collector and water storage tank together to become a single package that is easy to install everywhere.

The COP of a small ISAHP (1001, 250 W compressor input) designed by Huang and Chyng (2001) is $>2.5$ at ambient temperature $>25^{\circ} \mathrm{C}$. However, it can be further improved if the compressor can be shut down during high solar radiation periods.

An ISAHP is a heat pump with dual heat sources. It absorbs solar radiation and ambient heat simultaneously through the evaporator of the Rankine cycle. This means that the compressor must be turned on in order to make hot water no matter how high the solar radiation is. The present study intends to design a heat-pipe enhanced SAHP (called HPSAHP) which combines the performance of a heat pipe solar collector and a SAHP. When solar radiation is low, the compressor is turned on 


\section{Nomenclature}

$A_{\mathrm{c}} \quad$ heating area of the evaporator, $\mathrm{m}^{2}$

COP coefficient of performance of HPSAHP

$C_{p} \quad$ specific heat of water, $\mathrm{J} \mathrm{kg}^{-1}{ }^{\circ} \mathrm{C}^{-1}$

$E_{\mathrm{w}} \quad$ daily total energy collection, $\mathrm{J}$

$H_{\mathrm{t}} \quad$ daily total heating capacity, $\mathrm{MJ} / \mathrm{m}^{2} /$ day

$M \quad$ total mass of water in the storage tank, $\mathrm{kg}$

$R_{\mathrm{pw}} \quad$ heat-pipe thermal resistance, ${ }^{\circ} \mathrm{CW}^{-1}$

$T_{\mathrm{a}} \quad$ average ambient air temperature, ${ }^{\circ} \mathrm{C}$

$T_{\mathrm{e}} \quad$ average evaporation temperature, ${ }^{\circ} \mathrm{C}$

$T_{\mathrm{w}} \quad$ water temperature, ${ }^{\circ} \mathrm{C}$

$T_{\text {wall }} \quad$ collector wall temperature, ${ }^{\circ} \mathrm{C}$
$T_{\text {wi }} \quad$ initial water temperature, ${ }^{\circ} \mathrm{C}$

$T_{\text {wf }} \quad$ final water temperature, ${ }^{\circ} \mathrm{C}$

$t \quad$ time, $\mathrm{s}$

(UA) $)_{\mathrm{e}}$ daily overall heat transfer coefficient from ambient to collector, $\mathrm{J} /{ }^{\circ} \mathrm{C}$

$Q_{\text {in }} \quad$ heat input rate by electric heater, W

$q_{\text {in }} \quad$ heat input density by electric heater, $\mathrm{W} / \mathrm{m}^{2}$

$\alpha$ solar radiation absorb coefficient of the evaporator

$\eta \quad$ efficiency of HPSAHP heat pipe mode and a solenoidal valve is closed such that HPSAHP operates in heat-pump mode. When solar radiation is high, the compressor is turnd off and HPSAHP operates in heat-pipe mode without electricity consumption. Thus, the HPSAHP can achieve higher energy efficiency. The schematic diagram of HPSAHP is shown in Fig. 1.

\section{Process of HPSAHP}

HPSAHP operates in two modes: heat-pipe mode and heat-pump mode.

\subsection{Process of heat-pipe loop}

The flowchart for the process of the heat-pipe loop is shown in Fig. 1 in dashed lines. In heat-pipe mode operation, the compressor is turned off and the refrigerant di- rectly enters the condenser without passing through the compressor, after absorbing the heat from sun in the evaporator. The vapor is condensed in the condenser that is immersed in a hot water tank, and releases heat to the water. After that, the refrigerant passes through a solenoid valve and back to the evaporator. There is no electricity consumption during the heat-pipe mode operation. For absorbing heat from ambient air in heat-pump mode operation, the evaporator is designed in two parts. The refrigerant absorbs solar radiation only in the half part of the evaporator facing toward the sun. A check-valve (Va) is installed in between to avoid the refrigerant flowing to the other half instead of flowing into the condenser. In order to avoid the heat loss by a reverse flow from the condenser in the hot water tank to the absorber during nighttime or cloudy weather, another check valve $(\mathrm{Vc})$ is installed between the outlet of the evaporator and the inlet of the condenser.

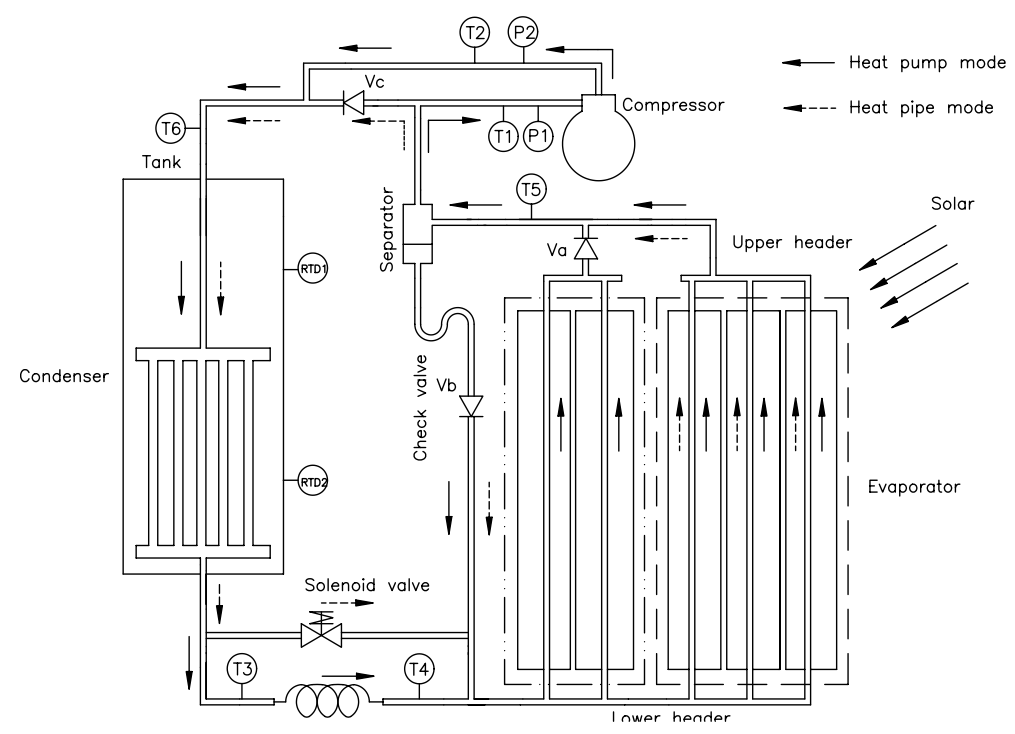

Fig. 1. Flow chart and schematic diagram of the HASHP. 


\subsection{Process of heat-pump loop}

In heat-pump mode operation, the solenoid valve is closed such that the refrigerant enters the compressor after absorbing the heat from solar radiation and ambient air. After being compressed, the vapor enters the condenser and then flows back to the evaporator through the capillary tube.

\section{Experimental setup}

\subsection{Prototype design}

The HPSAHP prototype used a bare collector/evaporator. The collector is of tube-in-sheet type using copper tube $(6 \mathrm{~mm}$ diameter) soldered on copper sheet $(0.4 \mathrm{~mm}$ thick). The size of the each sheet is $10 \mathrm{~cm} \times 180 \mathrm{~cm}$. Twenty one copper tube-sheets are used in the collector. The total surface area of the collector is $3.78 \mathrm{~m}^{2}$. The collector surface is a selective black surface. The round-shape collector is surrounding the water tank. All copper-in-tube plates are connected in parallel by two header pipes ( $20 \mathrm{~mm}$ diameter).

The evaporator/collector is designed in circular shape. Hence, it always absorbs both solar radiation and ambient air by the half part facing the sun and absorbs the ambient air energy only from the other half that is back the sun.

For convenience in experiment indoor, electric heating films are pasted on the back surface of the 11 copper plates to simulate incident solar radiation. The Rankine refrigeration cycle unit is mounted on the top of the HPASHP. A small R134a reciprocating-type hermetic compressor with piston swept volume $12 \mathrm{~cm}^{3}$ and rated input power $550 \mathrm{~W}$ is used.

The condenser heat exchanger is immersed in the storage tank and the design is tube-in-sheet type similar to the evaporator. Fifteen vertical copper tubes $(13 \mathrm{~mm}$ diameter) are connected in parallel by two circular header pipes ( $20 \mathrm{~mm}$ diameter). Water absorbs the condensation heat from the refrigerant vapor inside the copper tubes. The HPSAHP uses a 2401 tank for hot water storage.

A capillary tube $(200 \mathrm{~cm}$ length, $1.2 \mathrm{~mm}$ diameter $)$ is used for regulating the refrigerant flow in the Rankine refrigeration cycle. A filter is installed downstream of the condenser and an accumulator is installed downstream of the collector/evaporator for protecting the compressor from wet compression. A solenoid valve is installed at the outlet of the condenser for the operation of two different modes in the HPSAHP. Three check valves are installed in the system to prevent the refrigerant backflow. The prototype of the HPSAHP is shown in Fig. 2. Design specifications of the HPSAHP are listed in Table 1.

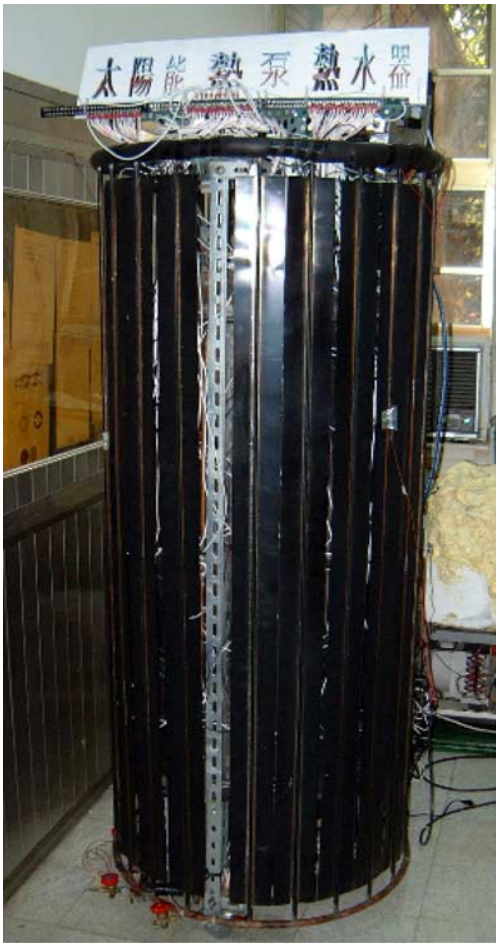

Fig. 2. Prototype of the HPASHP.

Table 1

Design specifications of HPSAHP

\begin{tabular}{|c|c|}
\hline Collector area & $\begin{array}{l}3.78 \mathrm{~m}^{2} \text { selective surface, unglazed } 21 \\
\text { tubes-in-sheet }\left(1.98 \mathrm{~m}^{2} \text { facing the sun; }\right. \\
1.8 \mathrm{~m}^{2} \text { back the sun) }\end{array}$ \\
\hline Water tank & $\begin{array}{l}2401(50 \mathrm{~cm} \text { diameter, } 120 \mathrm{~cm} \text { tall }) 6 \mathrm{~cm} \text { PU } \\
\text { insulation layer }\end{array}$ \\
\hline Rankine cycle & $\begin{array}{l}\text { Compressor/R } 134 \mathrm{a}, 550 \mathrm{~W} / 110 \mathrm{VAC} \\
12 \mathrm{~cm}^{3} / \mathrm{stroke} \\
\text { Condenser/tube bundles } \\
(15 \text { tubes, } 12.7 \mathrm{~mm} \text { i.d., } 1 \mathrm{~m} \text { long) }\end{array}$ \\
\hline
\end{tabular}

\subsection{Instrumentation}

Two T-type thermocouples are installed in the suction and discharge ports of the compressor for the temperature measurement, labeled as $T_{1}$ and $T_{2}$, respectively. Another two T-type thermocouples are installed at the upstream and the downstream of the capillary tube for the temperature measurement, labeled as $T_{3}$ and $T_{4}$, respectively. The other two T-type thermocouples are installed at the outlet of the evaporator and the inlet of the condenser for the temperature measurement, labeled as $T_{5}$ and $T_{6}$, respectively (see Fig. 1). Two RTD sensors are used to measure the water temperature in the tank. One is at one-third of the tank height from the bottom, and the other is at two-thirds 
of the tank height. Two pressure gages are used to measure the suction and the discharge pressures of the compressor, $P_{1}$ and $P_{2}$. The condensing temperature $T_{\mathrm{c}}$ is converted from the discharge pressure data $P_{1}$ using thermodynamic chart of R134a (ASHRAE, 1989). Since the pressure loss in the compressor suction line may be large, the evaporating temperature is determined from $T_{4}$. The input power of the electric heating film is varied by a transformer to simulate the solar radiation intensity. The heat input rate $\left(Q_{\text {in }}\right)$ of the electric heating films is measured by a power-meter. The total power input to the compressor is measured by a wattmeter.

\section{Test results}

The HPSAHP includes two modes. The two operational modes were tested separately first in order to analyze the performance of each mode. Then, a test for a hybrid mode is performed.

\subsection{Heat-pump mode}

In heat-pump mode operation, the solenoid valve is closed and the refrigerant enters the compressor after absorbing the energy from the solar radiation and the ambient air. After being compressed, the vapor enters the condenser and then flows back to the evaporator through the capillary tube.

The heat-pump operates on the principle of Rankine cycle, the same as the ISAHP. The compressor is always running during the heat-pump mode.

The heat-pump mode experiment is tested indoor. The final temperature is set at $55^{\circ} \mathrm{C}$ at which point the operation is terminated. The distribution of water tem- perature is not uniform in the tank. Thus, a water pump is used to mix the water before taking water temperature measurements. We used the electric heating to simulate the solar radiation absorbed by the evaporator. The heat input rate is converted into the heat input density, $q_{\text {in }}=$ $Q_{\text {in }} / A_{\mathrm{c}}$. The ambient temperature is between $21^{\circ} \mathrm{C}$ and $23^{\circ} \mathrm{C}$ during the test. The experimental result shows that the electricity consumption per liter of hot water is between 0.012 and $0.018 \mathrm{kWh} / 1$. COP of the HPSAHP in heat-pump mode varies from 2.5 to 3 and increases with increasing solar radiation, as shown in Fig. 3. COP is defined as follows

$\mathrm{COP}=\frac{M C_{p}\left(T_{\mathrm{wf}}-T_{\mathrm{wi}}\right)}{\text { Total electricity consumption }}$

where $M$ is the weight of the water $(240 \mathrm{~kg}) ; C_{p}$ is the specific heat of water; $T_{\mathrm{wf}}$ is the final water temperature; $T_{\text {wi }}$ is the initial water temperature.

The heat-pump mode operation of the HPSAHP is the same as the ISAHP. Huang and Chyng (2001) have derived an instantaneous correlation of ISAHP for the total energy absorption at the evaporator. For long-term performance, a correlation can thus be derived according to the similar procedure:

$C_{\text {day }} \equiv \frac{E_{\mathrm{w}}}{\left(H_{\mathrm{t}} \times A_{\mathrm{c}}\right)}=(\mathrm{UA})_{\mathrm{e}} \frac{T_{\mathrm{a}}-T_{\mathrm{e}}}{\left(H_{\mathrm{t}} \times A_{\mathrm{c}}\right)}+\alpha$

where $E_{\mathrm{w}}$ is the daily total energy collection in the tank minuses total electricity consumption of compressor $W_{\text {ele }} t$; (UA) $)_{\mathrm{e}}$ is the daily-total heat transfer coefficient from ambient air to the refrigerant. $H_{\mathrm{t}}$ is the daily total heating capacity defined as $H_{\mathrm{t}}=q_{\text {in }} t, \alpha$ is the solar absorption coefficient representing energy collection from solar radiation. The correlation is satisfactory and the test results as shown in Fig. 4.

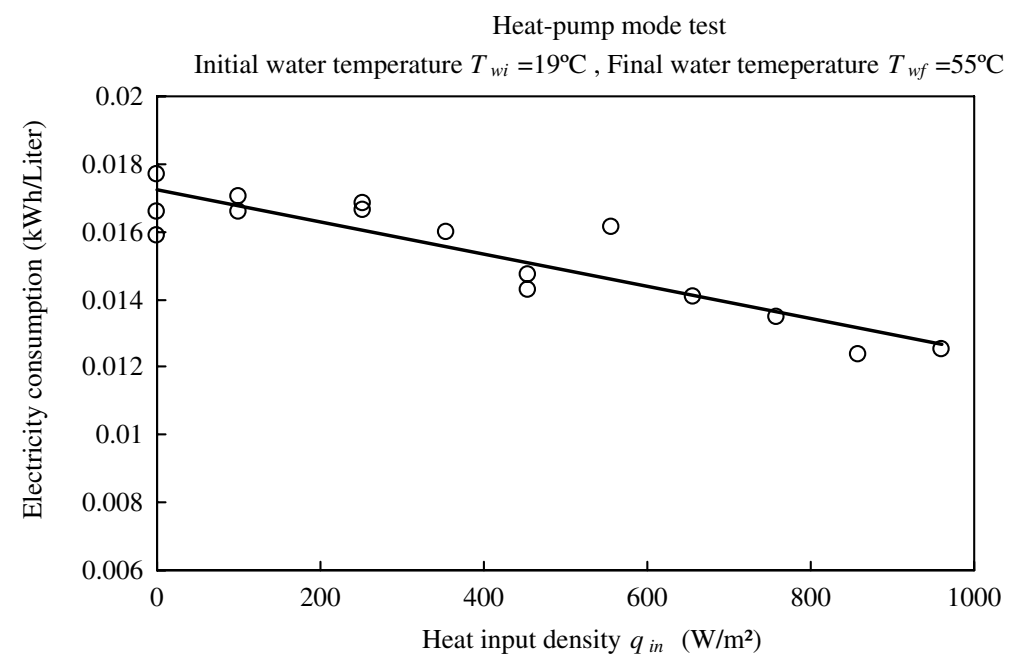

Fig. 3. Electricity consumption of the HPSAHP. 


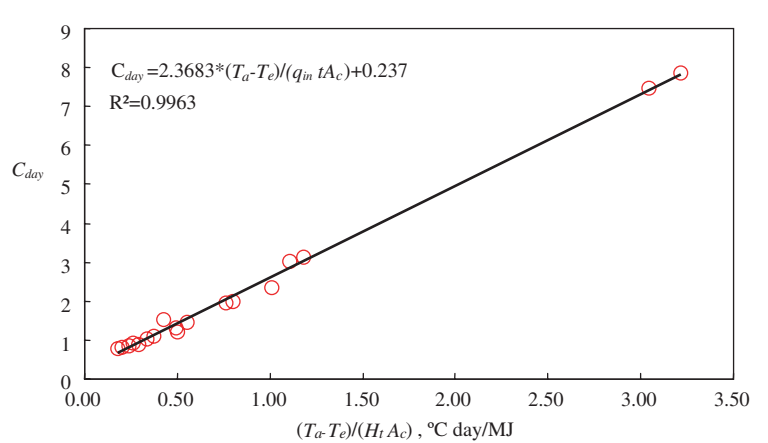

Fig. 4. Correlation of HPSAHP.

\subsection{Heat-pipe mode}

In heat-pipe mode operation, the solenoid valve is opened. The refrigerant absorbs the heat from the evaporator, and then flows into the condenser directly. It flows back to the evaporator through the solenoid valve after being condensed in the condenser. Many parameters influence the heat pipe mode performance including the refrigerant charge mass, water temperature, solar radiation etc. (Chi, 1976). We charged different refrigerant mass to test the performance (Fig. 5). The heat input density $q_{\text {in }}$ is controlled at the $500 \mathrm{~W} / \mathrm{m}^{2}$, and the heating time is fixed at $6 \mathrm{~h}$. The heat-pipe mode efficiency $\eta$ is defined as follows.

$\eta=\frac{M C_{p}\left(T_{\mathrm{wf}}-T_{\mathrm{wi}}\right)}{q_{\mathrm{in}} \times t \times A_{\mathrm{c}}}$

where $M$ is the weight of the water $(240 \mathrm{~kg}) ; q_{\text {in }}$ is the heat input rate by the electric heater; $t$ is heating time. The efficiency of heat-pipe mode was measured at different refrigerant charges. Fig. 5 shows that the efficiency does not change much for the charging between 3.5 and $6.5 \mathrm{~kg}$. The test was carried out for total heating time $6 \mathrm{~h}$ with heating power $500 \mathrm{~W} / \mathrm{m}^{2}$. The thermal resistance of the heat pipe from the evaporator plate

Heat-pipe mode test

Heating capacity $=500 \mathrm{~W} / \mathrm{m}^{2}$; Heating time: 6 hours; Initial water temperature $=24^{\circ} \mathrm{C}$

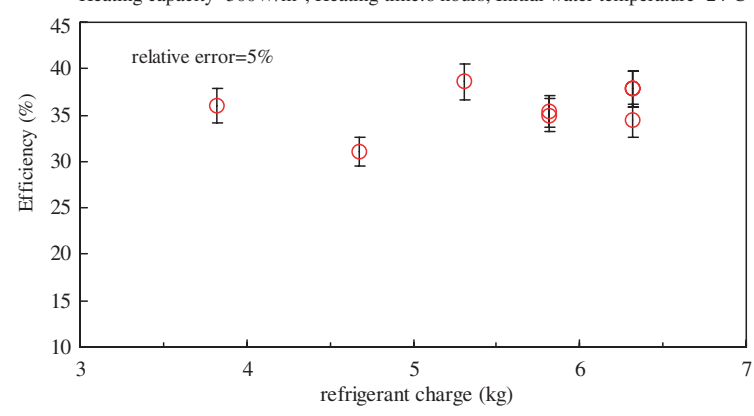

Fig. 5. Heat-pipe mode performance. to water is also determined, by varying total heating rate $Q_{\text {in }}$ from $400 \mathrm{~W}$ to $1600 \mathrm{~W}$. Six T-type thermocouples are used to measure the wall temperature. Two are installed on one plate of the evaporator. The thermal resistance $R_{\mathrm{pw}}$ is defined as follows:

$R_{\mathrm{pw}}=\frac{T_{\mathrm{wall}}-T_{\mathrm{w}}}{Q_{\mathrm{in}}}$

where $T_{\text {wall }}$ is the average wall temperature; $T_{\mathrm{w}}$ is the average water temperature; $Q_{\text {in }}$ is the heating rate. The thermal resistance $R_{\mathrm{pw}}$ remains between 0.01 and $0.02 \mathrm{~K} / \mathrm{W}$ when the heat input rate varies from $500 \mathrm{~W}$ to $1500 \mathrm{~W}$ (Fig. 6). Fig. 7 also shows the heat-pipe mode efficiency decreases with increasing initial water temperature. The test was carried out for total heating time $6 \mathrm{~h}$ with heat input density $q_{\text {in }}=500 \mathrm{~W} / \mathrm{m}^{2}$. The efficiency $\eta$ is defined as Eq. (3). The results show that the lower the initial water temperature the higher efficiency since the heat transfer rate is higher temperature difference between the refrigerant and water.

\subsection{Hybrid mode}

The hybrid mode performance includes the combined operation of heat pipe mode and heat pump mode. The

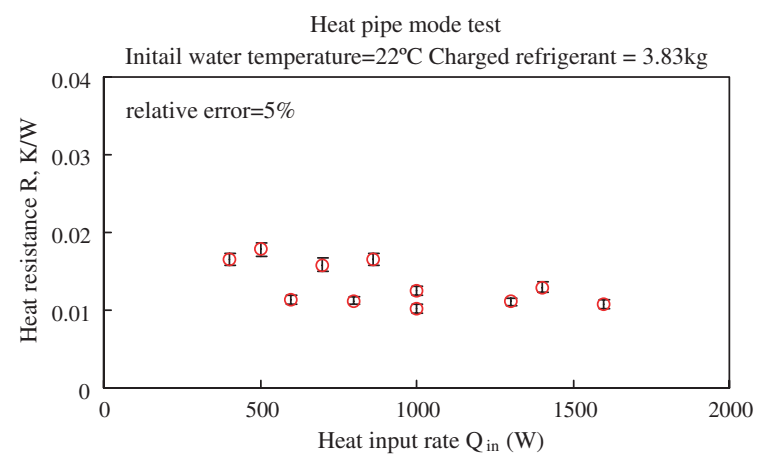

Fig. 6. Thermal resistance of heat-pipe mode.

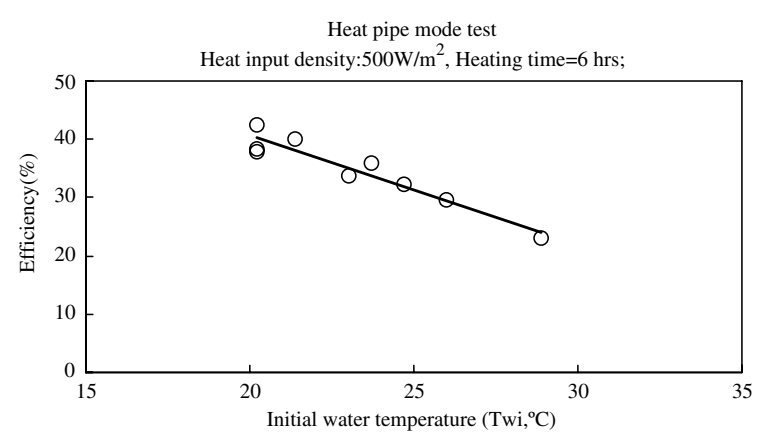

Fig. 7. Heat-pipe mode efficiency. 


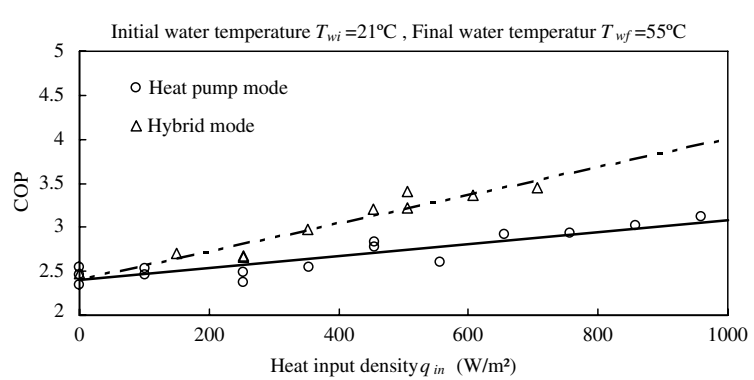

Fig. 8. HASHP hybrid-mode performance.

heat-pipe mode is changed to the heat-pump mode by switching off the solenoid valve. To keep a high performance for hybrid mode operation, a proper charge quantity of refrigerant is important. Fig. 5 shows that for heat-pipe mode operation, the weight of the refrigerant charge do not influence the efficiency very much. It was found experimentally that $3.825 \mathrm{~kg}$ is suitable for the heat-pump mode operation. The efficiency of the heat-pipe mode is satisfactory.

Fig. 7 indicates that the efficiency of heat-pipe mode operation is high (around 40\%) at low initial water temperature. Thus, for hybrid-mode operation, the heat pipe mode is suggested to adopt in the beginning of a day since the water temperature is low early in the morning.

The COP of the hybrid mode is tested indoor. We first start the heat-pipe mode for $4 \mathrm{~h}$ and then change to the heat-pump mode. The experiment is run at different heat input rates. The test results are shown in Fig. 8. $\mathrm{COP}$ of the hybrid mode is higher than heat-pump mode operation. COP varies from 2.5 to 3.5 . The improvement of hybrid-mode over the heat-pump mode only is obvious at high input density. This is due to the fact that heat-pipe mode is performed without electricity consumption. Thus, the difference between the COP of the hybrid-mode and the COP of the heat-pump mode is lager only when the heating capacity is higher.

\subsection{Outdoor test}

A new prototype HPSAHP-B (Fig. 9) is fabricated for verification by outdoor test. The principle of HPSAHP-B is the same as HPSAHP described before. The HPSAHP prototype used a bare collector/evaporator. The collector is tube-in-sheet type, using copper

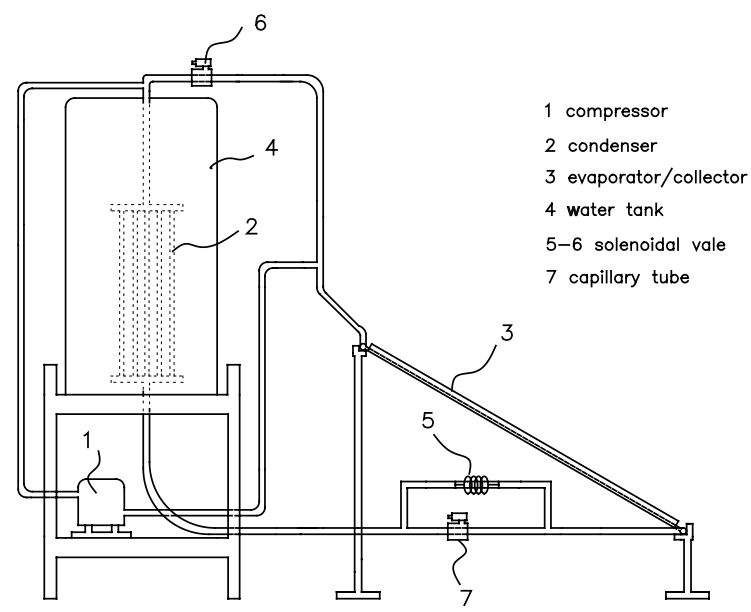

Fig. 9. Prototype design of the HPASHP-B.

Table 2

Design specifications of HPASHP-B

Collector area $1.21 \mathrm{~m}^{2}$ selective surface, unglazed

Water tank $1201(35 \mathrm{~cm}$ diameter, $105 \mathrm{~cm}$ tall) $6 \mathrm{~cm}$ PU insulation layer

Rankine cycle Compressor/R134a, 250W/110VAC, $5.29 \mathrm{~cm}^{3}$ Condenser/tube bundles

(10 tubes, $12.7 \mathrm{~mm}$ i.d., $0.5 \mathrm{~m}$ long)

tube $(6 \mathrm{~mm}$ diameter). Copper tubes are soldered on the copper sheets $(110 \mathrm{~cm} \times 110 \mathrm{~cm})$. The unglazed collector surface is made in wavy shape and is painted in black. The unglazed collector is set at a $23^{\circ}$ inclined angle in order to absorb more solar radiation. The condenser heat exchanger is immersed in the storage tank similar to HPSAHP. Ten vertical copper tubes $(13 \mathrm{~mm}$ diameter, $50 \mathrm{~cm}$ long) are connected in parallel by two circular header pipes ( $20 \mathrm{~mm}$ diameter). The HPSAHPB uses a 1001 tank for hot water storage. The specifications are listed in Table 2. The heat-pump mode and the hybrid-mode are tested separately. In order to test the COP of the heat-pump mode only, the compressor is turned on at AM10:00 and turned off when the water temperature is $53^{\circ} \mathrm{C}$. For hybrid mode test, the heatpipe mode is operated first in the early morning. Then, the heat-pipe mode is changed into the heat-pump mode when the solar radiation is smaller than $300 \mathrm{~W} / \mathrm{m}^{2}$ after PM12:00. The total solar radiation is measured by a pyr-

Table 3

Test results of HPASHP-B

\begin{tabular}{llllll}
\hline Mode & $\begin{array}{l}\text { Initial water } \\
\text { temperature }\left({ }^{\circ} \mathrm{C}\right)\end{array}$ & $\begin{array}{l}\text { Final water } \\
\text { temperature }\left({ }^{\circ} \mathrm{C}\right)\end{array}$ & $\begin{array}{l}\text { Daily total solar } \\
\text { radiation }\left(\mathrm{MJ} / \mathrm{m}^{2}\right)\end{array}$ & $\begin{array}{l}\text { Ambient } \\
\text { temperature }\left({ }^{\circ} \mathrm{C}\right)\end{array}$ \\
\hline Hybrid & 28.5 & 52.5 & 14.72 & 34.9 & COP \\
Heat pump & 27 & 53 & 15.55 & 35.9 & 2.32 \\
\hline
\end{tabular}


anometer which is installed at a $23^{\circ}$ inclined angle. The test result is shown in Table 3 . The COP increases obviously for the hybrid-mode. The COP of the hybrid-mode operation can reach 3.32 , an increase of $28.7 \%$ as compared to the heat-pump mode only (2.58).

\section{Conclusions and discussions}

HPSAHP operates as the heat-pump mode and the heat-pump mode. These two modes are tested separately. In the heat-pump mode, it shows that the COP increases with increasing heat input density. In the heat-pipe mode, the efficiency is tested in different refrigerant mass, heating capacity, and the initial water temperature. The thermal resistance of the heat pipe is between 0.01 and $0.02 \mathrm{~W} / \mathrm{K}$. The efficiency increases with decreasing initial water temperature.

How to decide the switching between the heat-pump mode and the heat-pipe mode is important for a HPSAHP. The present study shows that the overall performance can be better if the heat-pipe mode operates at lower temperature. Fig. 7 shows that COP becomes lower when the water temperature is higher than $30^{\circ} \mathrm{C}$. Hence, it is better to switch to heat-pump mode when the water temperature is over $30^{\circ} \mathrm{C}$. Fig. 8 also shows that the influence of the heat-pipe mode is obvious when the heat input density is large than $400 \mathrm{~W} / \mathrm{m}^{2}$. Therefore, the heat-pipe mode had better be operated at the water temperature $<30^{\circ} \mathrm{C}$ and at the heat input density $>400 \mathrm{~W} / \mathrm{m}^{2}$.

HPSAHP can operate without electricity consumption at high solar radiation using the heat-pipe mode operation. An outdoor test for the HPSAHP in the present study has shown that COP of the hybrid-mode operation can reach 3.32 , an increase of $28.7 \%$ as compared to the heat-pump mode COP (2.58). COP of the HPSAHP thus can be improved as compared to an ISAHP. The highest COP obtained in the present study is 3.5 which is thought to be high for a system using small compressor.

\section{Acknowledgments}

The present study was supported by Energy Commission, Ministry of Economic Affairs, and National Science Council, ROC, through Grant no. NSC91-2212E-002-077.

\section{References}

ASHRAE Handbook (1989). Fundamentals, American Society of Heating, Refrigerant and Air-Conditioning Engineers, Inc., 1989, pp. 17,22-17,23.

Chi, S.W., 1976. Heat Pipe Theory and Practice: A Sourcebook. Hemisphere Publishing Corporation.

Huang, B.J., Chyng, J.P., 1998. Integral type solar-assisted heat pump water heater. Renewable Energy Congress V II, 731734.

Huang, B.J., Chyng, J.P., 1999. Integral type solar-assisted heat pump water heater. Renewable Energy (16), 731-734.

Huang, B.J., Chyng, J.P., 2001. Performance characteristics of integral type solar-assisted heat pump. Solar Energy 71 (6), 403-414. 